\title{
Relationship between Serum Ferritin and Premature Atherosclerosis in Children with Beta Thalassemia Major
} Sylvia Triana*, Nelly Rosdiana, Aridamuriany D Lubis

*dr.sylvia1012@yahoo.co.id

Department of Child Health, Faculty of Medicine, Universitas Sumatera Utara, Medan, Indonesia Jl. Dr. Mansyur No.5 Padang Bulan, Medan Baru, Medan, North Sumatera, Indonesia

\begin{abstract}
Introduction : Atherosclerosis is asymptomatic and its complications are chronic, slowly progressive and cumulative. Serum ferritin tends to increase in $\beta$-thalassemia major cases; hence, it can become an indicator for premature atherosclerosis. . The risk of atherosclerosis is high in $\beta$-thalassemia major cases.

Objectives : To identify the relationship between serum ferritin and premature atherosclerosis in children with $\beta$-thalassemia major. This research also provided the prevalence and correlation of premature atherosclerosis between serum ferritin level and lipid profile

Material and Methods : This research was an analytical cross-sectional study in pediatric clinic Haji Adam Malik Hospital from July to November 2019. Echocardiography was used to measure carotid intima-media thickness, while serum ferritin and lipid levels were measured from laboratory analysis. Data analysis was done by using SPSS software. Mann-Whitney test was used to observe the relationship between serum ferritin and premature atherosclerosis, and Spearman correlation test was used to observe the correlation between serum ferritin and lipid.

Result : Among 35 research samples, 6 children (17\%) suffered from premature atherosclerosis with mean CIMT $0.6 \pm 0.27 \mathrm{~mm}$. The mean values of triglyceride in patients with and without atherosclerosis were 141 $(\mathrm{SD} 41.3) \mathrm{mg} / \mathrm{dl}$ and $117(\mathrm{SD} 41.8) \mathrm{mg} / \mathrm{dl}$ respectively $(\mathrm{p}=0.203)$. There was no significant relationship found between serum ferritin and premature atherosclerosis in children with $\beta$-thalassemia major $(p=0.708)$.
\end{abstract}

Published by IJRP.ORG. Selection and/or peer-review under responsibility of International Journal of Research Publications (IJRP.ORG)

Keywords: $\beta$-thalassemia major; premature atherosclerosis; serum ferritin; carotid intima media thickness

\section{Introduction}

Thalassemia is one of the most common genetic disorders in the world. It is caused by the inability of bone marrow to form protein needed by the body to produce hemoglobin (Potts and Mandleco, 2007). The disease was first discovered simultaneously in the United States and Italy between 1925 and 1927. Thalassemia was found to have spread across races in the Mediterranean, Middle East, India and to Southeast Asia (Windiastuti et al., 2018).

Beta thalassemia major is a genetically inherited (autosomal recessive) blood disorder characterized by the insufficiency and absence of hemoglobin beta chain synthesis - resulting in the decrease in hemoglobin levels in red blood cells, reduction in the production of red blood cells, and anemia (Galanello and Origa, 2010). Anemia in $\beta$-thalassemia is caused by the reduced production and short lifespan of erythrocyte (Arceci, Hann, and Smith, 2006). 
Nearly all children with homozygous and heterozygous $\beta$-thalassemia showed clinical symptoms from birth, growth failure, feeding difficulties, recurrent infections, and other general weaknesses (Galanello and Origa, 2010). Patients with severe thalassemia and do not receive blood transfusions may die at an early age from anemia complications (Batubara, Akib, and Pramita, 2004). Without blood transfusions at all, children with thalassemia will die at the age of 2 years. Children could die due to recurrent infections if they had been suffering from low $\mathrm{Hb}$ level. Nonetheless, if they lived until puberty, they would suffer from complications due to iron accumulation (Windiastuti et al., 2018).

Regular blood transfusions are able to increase survival rates, but can also result in iron excess which can build up in the heart, liver, and endocrine organs. Children who receive adequate transfusions may have normal growth and development, and usually without splenomegaly. People with thalassemia can have better health status by receiving earlier blood transfusions. However, the iron buildup in the body will become another problem (Gursel et al., 2012). The toxicity of iron in high doses is due to the ability to react with oxygen molecules and transfer electrons and produce intermediate oxygen species, which eventually causes the formation of more reactive radicals. These reactive radicals attach lipid, protein, and DNA, causing damages in cells - which will eventually appear as organ dysfunctions (Jabbar, Davison, and Muslin, 2007). If chelation therapy is effective, children may live normally until puberty and up to adulthood. On the other hand, inadequate chelation therapy will gradually lead to iron buildup. The effect will be observable in the first decade, such as not achieving adolescent growth spurts, suffering from heart, endocrine, and liver complications due to iron overload; including diabetes, hyperthyroidism, hypoparathyroidism and progressive liver failure. Furthermore, secondary sexually characteristics may appear late or not appear at all (Windiastuti et al., 2018).

According to the research done in Pakistan by Arshad and Hyder (2009), 70\% death of patients with $\beta$-thalassemia major were due to heart defects (Arshad and Hyder, 2009). Atherosclerosis is a slowly progressive disease that begins in childhood, where morphological changes in the blood vessel occur and they are characterized by gradual thickening of the tunica intima (Sherief et al., 2017). Premature atherosclerosis is heart complications, which often occur in children with $\beta$ thalassemia major due to chronic hemolysis and the increase in iron levels in the body (Gursel et al., 2012). Most patients with $\beta$-thalassemia major have risk of atherosclerosis with no significant early symptoms. At subclinical stage or asymptomatic, premature atherosclerosis can be detected by measuring carotid intima media thickness (CIMT) using ultrasonography (USG) or echocardiography (Dimiati and Lubis, 2014).

Premature atherosclerosis in children with thalassemia can occur due to dyslipidemia (Hassanin et al., 2015). Dyslipidemia is a condition where lipid profile was disrupted due to the increase in total cholesterol and LDL levels, decrease in HDL level, and increase in triglyceride level (Daniels and Couch, 2014). The condition is caused by plasma dilution due to anemia, increase in erythropoiesis activity accompanied by cholesterol uptake by the macrophages and histiocytes in reticuloendothelial system, impaired liver functions due to iron buildup, hormonal imbalance, and decrease lipolytic activities outside the liver (Amendola, Danise, and Tordisco, 2007). The increase in tunica thickness of intima-medica in the carotid artery is associated with the rise in triglyceride level and atherogenic index plasma (AIP). Atherogenic index plasma (AIP) is the marker of atherosclerosis process - calculated by the log formula of (triglycerides/HDL). The increase in AIP level was observed in Patients with thalassemia. Hypertriglyceridemia also causes the increase in 
HDL degradation, hence increase the risk of atherosclerosis. Based on the research in Egypt by Sherief et al., (2017). Triglyceride level in $\beta$-thalassemia major patients increased with the increase in serum ferritin level (Sherief et al., 2017).

There has not been prevalence data for premature atherosclerosis in in $\beta$-thalassemia major patients in Indonesia. Therefore, this finding became the background of this research, about the relationship between serum ferritin and atherosclerosis premature in children with $\beta$-thalassemia major.

\section{Methods}

This research was an analytical observational study with cross-sectional design to assess the relationship between serum ferritin and premature atherosclerosis in children with $\beta$-thalassemia major. This research was conducted in the polyclinic and pediatric inpatient room of Haji Adam Malik (HAM) hospital, Medan from July to November 2019. The research samples in this research were children with $\beta$-thalassemia major who received treatment at the Department of Children Medical Faculty Universitas Sumatera Utara - HAM hospital within the research period and met inclusion and exclusion criteria. Inclusion criteria were children with $\beta$-thalassemia major aged $2-$ 18 years old, with serum ferritin level $>1000 \mathrm{ng} / \mathrm{mL}$, and received blood transfusions for at least 6 months. Exclusion criteria were children with $\beta$-thalassemia major but did not receive blood transfusions, smoking and consuming alcohol.

The research began with the recording of personal data of the research subjects and their parents, as well as transfusion frequency and iron chelation therapy used. Blood sampling was done to assess serum ferritin and lipid profile. Prior to that, the parents were reminded by phone to have their children to fast for 12 hours before the test. Echocardiography examination was performed by a consultant pediatric cardiologist.

\subsection{Research ethics}

All the parents of the research subjects had given their consent to be involved in the research and undergo laboratory assessment, such as lipid profile, serum ferritin level, and echocardiography. This research has received approval from the Research Ethics Committee of Medical Faculty, Universitas Sumatera Utara and Haji Adam Malik hospital Medan, No 615/TGL/KEPK FK-USURSUP HAM/219.

\subsection{Data analysis}

The data recorded was processed and analyzed by using Statistical Package for the Social Sciences (SPSS) software. Bivariate analysis was performed to describe sample characteristic data. Categorical data was presented in the form of frequency distribution and percentage. While, numerical data was presented as average, standard deviation (SD), and minimum and maximum values. Spearman correlation test was used to observe the relationship between serum ferritin level and premature atherosclerosis, as well as to determine whether or not serum ferritin level has a correlation to lipid profile. The significance and confidence interval levels were at 95\%. 


\section{Results}

\subsection{Research subject data characteristic}

There were 35 children with beta thalassemia major involved in this study, where 19 children $(54.3 \%)$ were male and 16 children $(45.7 \%)$ were female. The average age of $\beta$-thalassemia major patients in this research was 9 years old, with 3 and 17 years old as the youngest and oldest age respectively. The average body height and weight of the research subjects were $122 \mathrm{~cm}$ and $25 \mathrm{~kg}$ respectively. There were 16 (45.7\%) children recorded with bad nutritional status, while 15 of them (42.9\%) had good nutritional status, and $4(11.4 \%)$ children had poor nutritional status. The demographic characteristic of research subjects can be seen in Table 1 .

Table 1. Research subject demographic characteristic

\begin{tabular}{lc}
\hline Demographic characteristic & $\mathbf{n}=\mathbf{3 5}$ \\
\hline Gender, $\mathrm{n}(\%)$ & $19(54.3)$ \\
Male & $16(45.7)$ \\
Female & $9.33(4.10), 3-17$ \\
Age, average (SD), years old & $121.69(21.75), 73-175$ \\
Body height, average (SD), cm & $24.64(10.71), 13-63$ \\
Body weight, average (SD), kg & $18.43(3.64)$ \\
Upper arm circumference, average (SD), cm & \\
Nutritional status, $\mathrm{n}(\%)$ & $15(42.9)$ \\
Good & $16(45.7)$ \\
Bad & $4(11.4)$ \\
Poor & $93.43(22.14)$ \\
Total cholesterol, average (SD), mg/dl & $35(100)$ \\
$<170 \mathrm{mg} / \mathrm{dl}, \mathrm{n}(\%)$ & $123.91(37.83)$ \\
Triglycerides, average (SD), mg/dl & $27(77.1)$ \\
$<150 \mathrm{mg} / \mathrm{dl}, \mathrm{n}(\%)$ & $8(22.9)$ \\
$\geq 150 \mathrm{mg} / \mathrm{dl}, \mathrm{n}(\%)$ & $50.26(15.04)$ \\
LDL, average (SD), mg/dl & $35(100)$ \\
$<110 \mathrm{mg} / \mathrm{dl}, \mathrm{n}(\%)$ & $26.40(7.99)$ \\
HDL, average (SD), mg/dl & $2(5.7)$ \\
$>40 \mathrm{mg} / \mathrm{dl}, \mathrm{n}(\%)$ & $33(94.3)$ \\
$\leq 40 \mathrm{mg} / \mathrm{dl}, \mathrm{n}(\%)$ & $2334.06(1035.88), 1007-5144$ \\
Ferritin, average (SD), min-max, ng/ml & $29(82.9)$ \\
CIMT, average (SD), min-max, mm & $0.62(0.27), 0.07-1.29$ \\
$>0.8 \mathrm{~mm}, \mathrm{n}(\%)$ & $6.17 .1)$ \\
$\leq 0.8 \mathrm{~mm}, \mathrm{n}(\%)$ & \\
\hline & \\
& \\
&
\end{tabular}

The average total cholesterol was 93 (SD 22.1) $\mathrm{mg} / \mathrm{dl}$. The overall cholesterol level of all research subjects was $<170 \mathrm{mg} / \mathrm{dl}$. The average triglyceride level was 124 (SD 37.8) mg/dl. There were $8(22.9 \%)$ subjects with triglyceride level $>150 \mathrm{mg} / \mathrm{dl}$. All children had LCL level $<110$ $\mathrm{mg} / \mathrm{dl}$ with an average of 50 (SD 15.0) $\mathrm{mg} / \mathrm{dl}$. Meanwhile, 33 (94.3\%) children had HDL level < 40 $\mathrm{mg} / \mathrm{dl}$, with an average of 26 (SD 7.9) $\mathrm{mg} / \mathrm{dl}$. 
The average ferritin level was 2334 (SD 1035.8) ng/ml. Based on CIMT size, there were 6 $(17.1 \%)$ children without premature atherosclerosis with the average CIMT size of all subjects was 06 (SD 0.27) $\mathrm{mm}$.

\subsection{Relationship between serum ferritin and premature atherosclerosis}

The average serum ferritin in the group of subjects with CIMT size $>0.8 \mathrm{~mm}$ (premature atherosclerosis) was 2323 (SD 700.8) ng/ml, whereas in the other group without premature atherosclerosis (CIMT $\leq 0.8 \mathrm{~mm}$ ) the average was 2336.1 (SD 1102.3) $\mathrm{ng} / \mathrm{ml}$. The relationship between serum ferritin and premature atherosclerosis is presented in Table 2.

Table 2. Relationship between serum ferritin and premature atherosclerosis

\begin{tabular}{lccc}
\hline CIMT & n & Ferritin, average (SD) & $\boldsymbol{P}$ \\
\hline$>0.8 \mathrm{~mm}$ & 6 & $2323(700.8)$ & 0.714 \\
$\leq 0.8 \mathrm{~mm}$ & 29 & $2336(1102.3)$ & \\
\hline Spearman correlation test & & &
\end{tabular}

By using Spearman correlation test, $\mathrm{p}$ value obtained was 0.714 ( $\mathrm{p}>0.05)$. Therefore, it was concluded that there was no significant relationships between serum ferritin and premature atherosclerosis in children with $\beta$-thalassemia major

\subsection{Relationship between serum ferritin and lipid profile}

The relationship between serum ferritin level and lipid profile was assessed by using Spearman correlation test. There were significant relationships observed, where between serum ferritin and total cholesterol, triglycerides, HDL and LDL, with $\mathrm{P}$ value $0.982,0.028,0.106$, and 0.939 respectively. The data is presented in Table 3.

Table 3. Relationship between serum ferritin and lipid profile

\begin{tabular}{lccc}
\hline Characteristic & Lipid profile & $\boldsymbol{P}$ & r \\
\hline \multirow{2}{*}{ Ferritin } & Total cholesterol & 0.982 & -0.004 \\
& Triglycerides & 0.028 & -0.314 \\
& HDL & 0.106 & 0.278 \\
& LDL & 0.939 & -0.013 \\
\hline
\end{tabular}

Spearman correlation test

\subsection{Lipid profile and atherosclerosis}

Lipid profile in the research subjects was related to atherosclerosis occurrence. In subjects with atherosclerosis, the average total cholesterol was 86 (SD 15.5) mg/dl. Meanwhile, in the subjects without atherosclerosis, the average total cholesterol was $95 \mathrm{mg} / \mathrm{dl}$, with $\mathrm{min} 57 \mathrm{mg} / \mathrm{dl}$ and $\max 150 \mathrm{mg} / \mathrm{dl}$. The average triglyceride levels in subjects with and without atherosclerosis were $142 \mathrm{mg} / \mathrm{dl}$ (min $103 \mathrm{mg} / \mathrm{dl}$ and $\max 212 \mathrm{mg} / \mathrm{dl}$ ) and $120 \mathrm{mg} / \mathrm{dl}$ (min $102 \mathrm{mg} / \mathrm{dl}$ and $\max 231 \mathrm{mg} / \mathrm{dl}$ ) respectively. The average LDL level in subjects with atherosclerosis was $43 \mathrm{mg} / \mathrm{dl}$ (min $30 \mathrm{mg} / \mathrm{dl}$ and $\max 57 \mathrm{mg} / \mathrm{dl}$ ). The average LDL level in subjects without atherosclerosis was $52 \mathrm{mg} / \mathrm{dl}$ (min $25 \mathrm{mg} / \mathrm{dl}$ and $\max 95 \mathrm{mg} / \mathrm{dl}$ ). As for HDL level, the subjects with atherosclerosis had an average of $28.5 \mathrm{mg} / \mathrm{dl}(\mathrm{min} 24 \mathrm{mg} / \mathrm{dl}$ and $\max 37 \mathrm{mg} / \mathrm{dl}$ ), whereas the subjects without atherosclerosis had an 
average value of $26 \mathrm{mg} / \mathrm{dl}(\min 11 \mathrm{mg} / \mathrm{dl}$ and $\max 46 \mathrm{mg} / \mathrm{dl}$ ). The differences in lipid profile of the research subjects with and without atherosclerosis are presented in Table 4.

Table 4. Lipid profile and atherosclerosis

\begin{tabular}{lccc}
\hline \multirow{2}{*}{ Lipid profile } & \multicolumn{2}{c}{ Premature atherosclerosis } & \multirow{2}{*}{$\boldsymbol{P}^{*}$} \\
\cline { 2 - 3 } & Yes (n=6) & No (n=29) & 0.397 \\
\hline Total cholesterol, average (SD), mg/dl & $86(15.5)$ & $95(23.2)$ & 0.203 \\
Triglycerides, average (SD), mg/dl & $142(41.4)$ & $120(36.7)$ & 0.168 \\
LDL, average (SD), mg/dl & $43(11.5)$ & $52(15.3)$ & 0.488 \\
HDL, average (SD), mg/dl & $29(4.9)$ & $26(8.5)$ & \\
*T-independent test & &
\end{tabular}

\section{Discussion}

Thalassemia is a type of hemolytic anemia that occurs due to disruptions in the synthesis of one or more goblin chain derivatives (Debaun, Frei-Jones, and Vichinsky, 2011). People with $\beta$ thalassemia major have risk of suffering from atherosclerosis without significant early symptoms. Premature atherosclerosis is a subclinical atherosclerosis occurs at an early age in thalassemia cases and eventually develops into coronary heart diseases (Ashar et al., 2015). Endothelial dysfunctions are the first anomaly to occur, followed by atherosclerosis process and cardiovascular diseases (Roscha and Libby, 2009; Sayed et al., 2012).

The study done in Egypt by Sherief et al., (2017) reported 57\% of male subjects with thalassemia, however there were no significant differences between the two gender $(\mathrm{P}=0.306)$ (Sherief et al., 2017). This result was also supported by other study done by Gursel et al., (2012) in Turkey, where 58\% of male subjects were reported to be with thalassemia with P value 0.37 (Gursel et al., 2012). In this research, over half of the subjects (54.3\%) with thalassemia were male. However, there were no significant differences between gender and $\beta$-thalassemia major.

Sherief et al., (2017) reported the average age in their research study was 9.5 (SD 3.7) years old (Sherief et al., 2017). This result was almost similar to the study by Gursel et al., (2012), who reported the average age of 10.84 (SD 4.38) years old in their research subjects with thalassemia (Gursel et al., 2012). In this study, the average age of thalassemia research subjects was 9 (SD 4.1) years old. The study done by Tantawy et al., (2009) in Egypt reported the correlation between CIMT and age with $P$ value 0.03 , where there was a size increase by $0.07 \mathrm{~mm}$ per 10 years of age increase (Tantawy et al., 2009).

The research done by Sherief et al., (2017) reported the average height of research subjects was $114.44 \mathrm{~cm}$ (Sherief et al., 2017). A different study by Gursel et al., (2012) reported the average body height of the research subjects in their study was $129.44 \mathrm{~cm}$ (Gursel et al., 2012). In this study, the average body height of the research subjects was $122 \mathrm{~cm}$. However, in this study, there was no comparison of body height between patients with and without thalassemia.

As for nutritional status, Sherief et al., (2017) reported that subjects with bad nutritional status had average BMI 18.1 (SD 2.2) $\mathrm{kg} / \mathrm{m}^{2}$. However, there was no significant relationship statistically $(\mathrm{P}=0.191 .6)$. Similarly, Gursel et al., (2012) reported average BMI 17.34 (SD 3.03) kg/ $\mathrm{m}^{2}$ and there was no significant relationship between nutritional status and thalassemia $(\mathrm{P}=0.24)$. In this research, the highest recorded nutritional status of the research subjects was at bad level (45.7\%). Subjects 
with bad and poor nutritional status in this study were found with organomegaly and upper arm circumference of less than 5-percentile.

This study reported $17 \%$ incidence of premature atherosclerosis in $\beta$-thalassemia major cases with an average CIMT of $1.03 \mathrm{~mm}$. This result was almost similar to the study done by Abaza et al., (2017) in Egypt, in which premature atherosclerosis incidence was reported to be at $19 \%$ and the average CIMT was 0.8 (SD 0.16) mm (Abaza et al., 2017). The study by Gursel et al., (2012) in Turkey showed a significant increase in CIMT level in the study group compared to the control group -0.56 (SD 0.06) mm against 0.48 (SD 0.05) $\mathrm{mm}, \mathrm{P}<0.001$ (Gursel et al., 2012). The research done by Tantawy et al., (2009) showed the average CIMT in patients with thalassemia was 0.73 $\mathrm{mm}$, which was higher than the average in control group at $0.63 \mathrm{~mm}$ (Tantawy et al., 2009). Risk factors for atherosclerosis were hypercholesterolemia, hypertension, diabetes, smoking, family history of premature coronary heart disease, and endothelial dysfunctions (Davignon and Ganz, 2004).

The mechanism of the thickening of carotid tunica intima blood vessel was associated with the rise in triglyceride level, which occurred due to plasma dilution as the result of anemia and increase in erythropoiesis activities (Amendola, Danise, and Tordisco, 2007). Dyslipidemia in thalassemia patients was characterized by low levels of total cholesterol, HDL, and LDL, whereas higher triglyceride level than normal individuals (Mansi and Aburjal, 2008). A past study by Al Quobaili and Asali (2004) in Syria showed an increase in triglyceride level in $\beta$-thalassemia major patients (Al Quobaili and Asali, 2004). Another study in Iran by Sham et al., (2010) reported higher triglyceride level in thalassemia patients than control group (Sham et al., 2010). However, the study done by Maioli et al., (1984) and Haghpanah et al., (2010) reported no significant differences between triglyceride leveIs in thalassemia patients and healthy population (Maioli et al., 1984 and Haghpanah et al., 2010). In this research, the average triglyceride levels in thalassemia patients with and without atherosclerosis were 141 (SD 41.3) $\mathrm{mg} / \mathrm{dl} 117$ (SD 41.8) $\mathrm{mg} / \mathrm{dl}$ respectively, with $\mathrm{P}=0.203$. There was no increase in triglyceride level in the atherosclerosis group. This could be observed from the minimum and maximum levels of triglyceride in atherosclerosis group, which were $103 \mathrm{mg} / \mathrm{dl}$ and $212 \mathrm{mg} / \mathrm{dl}$ respectively. Therefore, not all patients with thalassemia and premature atherosclerosis had high triglyceride level in the research.

This research obtained low total cholesterol, LDL and HDL levels in subjects both with and without atherosclerosis. The average cholesterol level in this study was 86 (SD 15.5) mg/dl and 95 (SD 23.3) $\mathrm{mg} / \mathrm{dl}$ in the groups with and without atherosclerosis respectively. The decrease in cholesterol level in thalassemia patients was related to the increase in erythropoiesis activities, which caused cholesterol uptake by the macrophages and histiocyte in the reticuloendothelial system. Hence increased the need in cholesterol. Moreover, it could happen due to the excess iron and oxidative stress (Ragab, Safan, and Sherif, 2014; Sherief et al., 2017).

The average LDL levels in this research were 43 (SD 11.5) $\mathrm{mg} / \mathrm{dl}$ and 52 (SD 15.3) mg/dl in the subjects with atherosclerosis and without atherosclerosis respectively. This is similar to the study done by Maioli et al., (1984) and Sherief et al., (2017) in Italy and Egypt respectively, where they stated the decrease in LDL level in thalassemia patients (Maioli et al., 1984; Sherief et al., 2017). The average HDL levels in this study were also low in both subject groups with atherosclerosis (29 (SD 4.9) $\mathrm{mg} / \mathrm{dl})$ and without atherosclerosis (26 (SD 98.5) $\mathrm{mg} / \mathrm{dl})$. One of the lipid profiles that shows pro-atherogenicity was low HDL value, which was a prognostic factor in the risk of heart defects (Mansi and Aburjal, 2008). This is aligned with the study done by Ashar et 
al., (2015) in Pakistan, which was the first research to observe lipid level in $\beta$-thalassemia major patients. The result showed low levels of total cholesterol, LDL, and HDL levels in those patients, along with the increase in triglyceride level and TC : HDL ratio (Ashar et al., 2015). This could happen because a few mechanisms, such as plasma dilution from anemia, increase in erythropoiesis causing cholesterol uptake by the macrophages and histocytes in the reticuloendothelial system, heart disruptions from iron overload, macrophage activities with the release in cytokines, and hormonal disorders (Al Quobaili and Asali, 2004; Chrysohoou, Panagiotakos, and Pitasavos, 2004; Haghpanah et al., 2010).

The average serum ferritin in this study was 2334 (SD 1035.8) $\mathrm{ng} / \mathrm{ml}$, where 6 subjects with atherosclerosis had serum ferritin level of 2323 (SD 700.9) $\mathrm{ng} / \mathrm{ml}$ and 29 subjects without atherosclerosis had serum ferritin level of 2336 (SD 1102.4) $\mathrm{ng} / \mathrm{ml}$. The $\mathrm{P}$ value obtained was 0.708 $(\mathrm{P}>0.05)$, hence no significant relationships were observed between serum ferritin and premature atherosclerosis in children with $\beta$-thalassemia major. The study done by Cheung, Chow, and Chan (2006) stated that ferritin level was not correlated to the degree of artery thickness and endothelial dysfunctions in thalassemia cases. Low correlation between iron storage in the liver and ferritin level was found in patients receiving iron chelation therapy (Cheung, Chow, and Chan, 2006). The study done by Gursel et al., (2012) reported no relationship between serum ferritin level and CIMT in both study and control groups. The result of the study showed that the accumulation of iron in cellular level was more important than high ferritin level in the development of atherosclerosis (Gursel et al., 2012). The study done by You, Archacki, and Angheloiu (2003) showed the expression of ferritin chain was significantly more pronounced in atherosclerosis coronary arteries than in normal arteries (You, Archacki, and Anghekoiu, 2003). In $\beta$-thalassemia major patients, pathological accumulation of iron may contribute to the development of atherosclerosis (Gursel et al., 2012). High content of iron and free radicals had higher risk of atherosclerosis incidence than the increase in ferritin level (Anca, Arica, and Ozer, 2010).

This research was the first to be done in Indonesia to assess the correlations between thickness of CIMT as well as serum ferritin and premature atherosclerosis, although the results were indicating weak significance. Nonetheless, this could become a reference for further studies to find other methods to determine the iron storage in the bodies of $\beta$-thalassemia major patients as guidance for the appropriate iron chelation therapy. Moreover, to increase the awareness to cardiovascular diseases.

\section{Conclusion}

Serum ferritin level did not have a significant relationship with premature atherosclerosis in $\beta$-thalassemia major patients.

\section{Acknowledgements}

The author would like to thank all the staff in the Faculty of Medicine, Universitas Sumatera Utara for the extensive support during the study. 


\section{References}

Abaza SE, Salam AA, Baz AA, Mohamed AA. Carotid doppler ultrasonography as a screening tool of early atherosclerotic changes in children and young adults with $\beta$ - Thalassemia major. J Ultrasound. 2017; 20:301-308.

Anca V, Arica S, Ozer C. Serum lipid values in children with beta thalassemia major. Pediat Theurapeut. 2010;18:93-8.

Al Quobaili FA, Asali IEA. Serum level of lipids and lipoproteins in Syrian patients with $\beta$-Thalassemia major. Saudi Med J. 2004;25(7):871-75

Amendola G, Danise P, Tordisco N. Lipid profile in Thalassemia intermedia patients : correlation with erythroid bone marrow activity. Int J Lab Hematol. 2007;29:172-6.

Arceci RJ, Hann IM, Smith OP. Pediatric Hematology. Edisi ke-3.Australia : Blackwell Publishing; 2006. h.281-301.

Ashar S, Sultan S, Irfan SM, Sheeraz A. Serum fasting lipid profile in children and adolescents with $\beta$-Thalassemia mayor in southern Pakistan. Malaysian J Pathol. 2015;37(3):233-238.

Arshad MS, Hyder SN. Evidence of abnormal left ventricular function in patients with thalassaemia major an echocardiography based study. J Pediatr Cardiol. 2009;21(2):37-41.

Batubara JRL, Akib A, Pramita D. Delayed puberty in thalassemia major patient. Paedriatrica Indonesiana. 2004;7-8;143-8.

Cheung YF, Chow PC, Chan GC. Carotid intima media thickness is increased and related to arterial stiffness in patients with beta thalassemia major. Br J Hematol. 2006;135:732-4.

Chrysohoou C, Panagiotakos DB, Pitsavos C. Distribution of serum lipids and lipoproteins in patients with beta thalassaemia major: an epidemiological study in young adults from Greece. Lipid Health Dis. 2004; 3:3.

Daniels S, Couch S. Lipid disorders in children and adolescents. In: Sperling M, editor. Pediatric endocrinology. 4th ed. Philadelphia: Elsevier. 2014.p.1015

Davignon J, Ganz P. Role of endothelial dysfunction in atherosclerosis. AHA journals. 2004;III:27-32.

Debaun MR, Frei-Jones M, Vichinsky E. Haemoglobinopathies. In: Kliegman RM, Stanton BF, St. Geme III JW, Schor NF, Behrman RE, editors. Nelson textbook of pediatrics. 20 nd edition. Philadelphia: Saunders Elsevier; 2011. h. 2349-52

Dimiati H, Lubis SY. Gangguan jantung pada anak penderita talasemia mayor. Jurnal Kedokteran Syiah Kuala. 2014;14:15966.

Galanello R, Origa R. Beta-thalassemia. Orphanet J Rare Dis. 2010;5(11):1-15.

Gursel O, Kurekci AE, Tascillar E, Ileri T, Altun D, Tapan S et al. Premature atherosclerosis in children with $\beta$ Thalassemia major. J pediatr Hematol Oncol. 2012;34:630-34.

Haghpanah S, Davani M, Samadi B, Ashrafi A, Karimi M. Serum lipid profiles in patients with beta-thalassemia mayor and intermedia in southern Iran. J Res Med Sci. 2010;15(3):150-54.

Hassanin AL, Elgindi HD, El Wakeel MA, El Kassas GM, Amer AF, Abu Shady MM et al. Disturbances of lipid profile and serum feritin levels in thalassemic children. Current Science International. 2015;4 (2):178-81.

Jabbar DA, Davison G, Muslin AJ. Getting the iron out: Preventing and treating heart faliure in transfussion dependent thalassemia. Cleveland Clinic Journal of Medicine. 2007;7:807-8.

Maioli M, Cuccuru GB, Pranzetti P, Pacifico A, Cherchi GM. Plasma lipids and lipoproteins pattern in beta-thalassemia major. Acta Haemat. 1984;71:106-110.

Mansi M, Aburjal TA. Lipid profile in Jordanian children with $\beta$ thalassemia mayor. Int J Hematol Oncol. 2008;18:93-8.

Potts SJ, Mandleco BL. Pediatric nursing : Caring for Children and their families. 2ndedition. New York : Thomson Coorporation. 2007. h. 251-55.

Ragab S, Safan M, Sherif A. Lipid profiles in $\beta$ thalassemic children. Menoufia Med J. 2014;27:66-72.

Roscha V, Libby P. Obesity, inflammation, and atherosclerosis. Nat Rev Cardiol. 2009;6:399-409.

Sayed S, Maher S, Adel G, Hamdy L. Lipid profile in children with $\beta$ - Thalassemia mayor. Egptian Journal of Haematology. 2012;37:183-6.

Sherief LM, Dawood O, Ali A, Sherbiny HS, kamal NM, Elshanshory M et al. Premature atherosclerosis in children with beta-thalassemia major : New diagnostic marker. BMC Pediatrics. 2017;17:69.

Sham S, Ashtiani MT, Monajemzadeh M, Koochakzadeh L, Irani H, Jafari F et al. Evaluation of serum insulin, glucose, lipid profile and liver function in $\beta$-Thalassemia major patients and their correlation with iron overload. Labmedisine. 2010;41(80):219-22.

Tantawy AAG, Adly AAM, El Maaty MGA, Amin SAG. Subclinical atherosclerosis in young $\beta$-Thalassemia major patients. Hemoglobin. 2009 ;35(6):463-74.

Windiastuti E, Nency YM, Mulatsih S, Sudarmanto B, Ugrasena IDG. Hemoglobin abnormal. Dalam: Bambang HP, Sutaryo, Ugrasena IDG, Windiastuti E, Abdulsalam M, editor. Buku ajar hematologi onkologi anak IDAI. Jakarta: Badan Penerbit Ikatan Dokter Anak Indonesia; 2018. h. 64-84.

You SA, Archacki SR, Angheloiu G. Proteomic approach to coronary atherosclerosis shows feritin light chain as a significant marker: evidence consistent with iron hypothesis in atherosclerosis. Physiol Genomics. 2003;13:25-30. 